\title{
Spirometry-related pain and distress in adolescents and young adults with cystic fibrosis: The role of acceptance
}

\author{
Annabelle Casier MSc ${ }^{1}$, Liesbet Goubert $\mathrm{PhD}^{1}$, Tine Vervoort $\mathrm{PhD}^{1}$, Marleen Theunis MSc ${ }^{2}$, Danielle Huse MSc ${ }^{3}$, \\ Frans De Baets $\mathrm{PhD}^{4}$, Dirk Matthys $\mathrm{PhD}^{4}$, Geert Crombez $\mathrm{PhD}^{1}$
}

\begin{abstract}
A Casier, L Goubert, T Vervoort, et al. Spirometry-related pain and distress in adolescents and young adults with cystic fibrosis: The role of acceptance. Pain Res Manag 2013;18(6):286-292.

OBJECTIVE: To investigate the occurrence of spirometry-related pain and distress in adolescents and young adults with cystic fibrosis (CF), and to investigate the role of acceptance of illness in spirometry-related pain and distress.

METHODS: A total of 36 adolescents and young adults with CF (12 to 22 years of age) completed a questionnaire assessing acceptance of illness. Spirometry-related distress was assessed using self-report (ie, anxiety/worry about the procedure) and physiological outcomes (ie, heart rate and heart rate variability) before spirometry. Spirometry-related pain was assessed using self-report (ie, expected pain and pain-related thoughts). Self-reported distress and pain during spirometry were also assessed.

RESULTS: Eighty-nine per cent of subjects reported distress before spirometry, $67 \%$ experienced distress during spirometry, $28 \%$ expected pain during spirometry and $22 \%$ actually experienced pain. Interestingly, partial correlations revealed that more acceptance was related to less expected pain and pain-related thoughts. Acceptance, however, was unrelated to distress, anxiety and pain during spirometry.

DISCUSSION: The present study suggests that a non-negligible number of adolescents and young adults with CF experience pain and distress during spirometry. Furthermore, results indicate that acceptance may play a protective role in the more indirect consequences of CF such as expected pain and pain-related thoughts during medical procedures. Acceptance, however, was not related to distress before and during spirometry, nor to experienced pain. These findings contribute to the increasing evidence that acceptance may play a protective role in managing the consequences of living with CF.
\end{abstract}

Key Words: Acceptance; Cystic fibrosis; Distress; HRV; Pain

\section{La douleur et la détresse liées à la spirométrie chez des adolescents et des jeunes adultes atteints de fibrose kystique : le rôle de l'acceptation}

OBJECTIF : Examiner l'occurrence de douleur et de détresse liées à la
spirométrie chez des adolescents et des jeunes adultes atteints de fibrose
kystique (FK) ainsi que le rôle de l'acceptation de la maladie à l'égard de
cette douleur.
MÉTHODOLOGIE : Au total, 36 adolescents et jeunes adultes atteints
de FK (de 12 à 22 ans) ont rempli un questionnaire évaluant leur accepta-
tion de la maladie. Les chercheurs ont évalué la détresse liée à la spirométrie
d'après les autoévaluations (c.-à-d. anxiété et inquiétude vis-à-vis de
l'intervention) et les issues physiques (p. ex., fréquence cardiaque et
variabilité du rythme cardiaque) avant la spirométrie. Ils ont évalué la
douleur liée à la spirométrie d'après les autoévaluations (c.-à-d. douleur
prévue et pensées liées à la douleur). Ils ont également évalué la détresse et
la douleur autodéclarées pendant la spirométrie. RÉSULTATS : Quatre-vingt-neuf pour cent des sujets ont déclaré de la détresse avant la spirométrie, $67 \%$ en ont ressenti pendant la spirométrie, $28 \%$ s'attendaient à en ressentir pendant la spirométrie et $22 \%$ en ont vraiment ressenti. Fait intéressant, des corrélations partielles ont révélé qu'une plus grande acceptation était liée à une diminution de la douleur prévue et des pensées liées à la douleur. L'acceptation n'était toutefois pas liée à la détresse, à l'anxiété et à la douleur pendant la spirométrie.

EXPOSÉ : D'après la présente étude, un nombre non négligeable d'adolescents et de jeunes adultes atteints de FK ressentiraient de la douleur et de la détresse pendant la spirométrie. De plus, les résultats indiquent que l'acceptation pourrait jouer un rôle protecteur à l'égard des conséquences plus indirectes de la FK, telles que la douleur prévue et les pensées liées à la douleur pendant les interventions médicales. L'acceptation n'était toutefois pas liée à la douleur avant et pendant la spirométrie ni à la douleur ressentie. Ces observations s'ajoutent aux données probantes croissantes selon lesquelles l'acceptation pourrait jouer un rôle protecteur pour affronter les conséquences d'une vie avec la FK.

To prevent or delay damage to their health, patients undergo a complex and time-consuming daily treatment regimen (ie, physiotherapy, exercise, nutritional management, aerosol therapy, drug treatment) combined with regular routine hospital visits; occasionally, hospitalization is necessary (4-7). Routine hospital visits include several medical procedures such as weight and height measurement, sputum culture, physical examination, chest $\mathrm{x}$-rays and spirometry. Undergoing medical procedures may be a distressing experience for children, adolescents and young adults with CF $(6,8)$. This may particularly be the case for spirometry, a standard noninvasive procedure used to track changes in the lungs (9). Spirometry entails maximal inhalation followed by forced and maximal exhalation while the lips are placed around a mouthpiece (8). Procedure-related distress may be young adults (3).

\footnotetext{
${ }^{1}$ Department of Experimental-Clinical and Health Psychology, Ghent University; ${ }^{2}$ Cystic Fibrosis Centre, University Hospital Ghent, Ghent; ${ }^{3}$ Belgian Cystic Fibrosis Association, Brussels; ${ }^{4}$ University Hospital Ghent, Department of Pediatrics and Medical Genetics, Ghent, Belgium Correspondence: Ms Annabelle Casier, Department of Experimental-Clinical and Health Psychology, Ghent University, Henri Dunantlaan 2, Ghent 9000, Belgium. Telephone 32-0-9-264-96-01, fax 32-0-9-264-64-89, e-mail annabelle.casier@ugent.be
} 
due to experienced discomfort, undue fatigue and/or dizziness (or even syncope), but also difficulty with the technical performance of the manoeuvres and intolerance of the procedure due to substantial and ongoing anxiety, and/or worry regarding health status and well-being $(6,8-10)$. Furthermore, spirometry may evoke not only distress, but also pain (eg, chest pain) $(3,8)$. Given the possibility of pain and distress during spirometry, the potential detrimental effects of pain and distress, and the fact that spirometry is an important medical procedure that individuals with CF must regularly undergo, it is important to verify whether spirometry, in fact, evokes considerable levels of pain and distress $(6,8,9)$. To the best of our knowledge, the occurrence of spirometry-related pain and distress has yet to be investigated.

Extensive research investigating a variety of invasive and noninvasive medical procedures has shown that assessing and understanding procedural pain and distress in adolescents and young adults with chronic illness is essential because it may interfere with cooperation during the procedure, cause memory and attentional biases toward negative aspects of the procedure, influence the management of subsequent medical procedures, cause persistent conditioned distress and negatively impact quality of life (11-13). Adequate management of procedure-related pain and distress, which may involve pharmacological (eg, analgesics) as well as nonpharmacological interventions (eg, distraction, cognitive-behavioral interventions) is, therefore, of the utmost importance $(3,5)$. Previous research has identified several risk factors that contribute to increased pain and distress during medical procedures including younger age, female sex, negative memory and higher expectations of pain and distress (12-14). However, it is equally important to gain insight into the factors that protect against pain and distress. Understanding these protective factors may guide the prevention of pain and distress during medical procedures and/or attenuate the short-and long-term negative consequences of pain and distress. To date, only a few studies have investigated factors that may protect against procedure-related pain and/or distress. Protective factors that have been identified include the use of control, distraction and humour $(5,15)$.

Another potentially protective factor for procedure-related pain and distress is acceptance. Acceptance can be defined as "recognizing the need to adapt to chronic illness while perceiving the ability to tolerate the unpredictable, uncontrollable nature of the disease and handle its aversive consequences" (16). Research investigating the role of acceptance conducted across several pediatric chronic conditions, such as chronic pain, juvenile arthritis and sickle cell disease, has revealed that greater acceptance is related to better overall functioning. Specifically, higher acceptance has been associated with less anxiety, less depression, less disability and a better quality of life $(17-20)$. To date, only two studies, reporting the same associations, specifically studied acceptance in adolescents and young adults with CF (21,22). Furthermore, research involving nonclinical samples has demonstrated that higher acceptance is related to less negative emotions during negative experiences $(23,24)$.

To our knowledge, there are no studies available that have assessed the impact of acceptance on procedure-related distress and pain in the context of CF. The present study, therefore, aimed to explore the occurrence of spirometry-related pain and distress, as assessed by selfreport and physiological outcomes, and to investigate the explanatory value of acceptance in this pain and distress within a sample of adolescents and young adults with CF. Consistent with previous research investigating acceptance, it was hypothesized that greater acceptance is related to less expected/experienced pain before/during spirometry and to lower levels of distress before/during spirometry.

\section{METHODS}

\section{Participants}

Adolescents and young adults with CF (12 to 22 years of age) were recruited from the University Hospitals of Antwerp, Brussels and Ghent (Belgium), and the Sint-Vincentius Hospital (Antwerp, Belgium). Participants were required to fulfil the following criteria to be eligible for the study: understanding the Dutch language; no developmental disorder; and no (planned) lung transplantation. Adolescents and young adults who had undergone or were awaiting lung transplantation were not included because they are often in an extreme situation that is very different from the situation of individuals in the pretransplant period (eg, very high level of symptoms, being terminally ill, intertwinement of end-of-life issues and hope of transplantation). Seventy-eight adolescents and young adults were either invited to participate by letter and/or were approached by the psychologist from the respective hospital during routine clinic visits (time period of recruitment: 13 months). Of the 78 adolescents and young adults who were invited, 52 agreed to participate and were contacted by telephone by a research assistant (response rate 66.67\%). The main reasons cited for not participating were lack of time, lack of motivation, being overloaded with participating in scientific research or not wanting to be unnecessarily confronted with the disease. Twelve adolescents and young adults could not be enrolled in the study because they did not visit a hospital during the period of recruitment. Of the 40 adolescents and young adults who participated in the present study, four were excluded because their observed spirometry procedure deviated from the standard spirometry procedure. The final sample consisted of 36 adolescents and young adults with CF (17 male [47.22\%]). The mean ( \pm SD) age of the participants was $17.58 \pm 3.25$ years. All adolescents and young adults were Caucasian. To determine disease severity, the United States CF Foundation guidelines for severity of lung disease were used (25). Mean disease severity reflected mild lung disease (forced expiratory volume in $1 \mathrm{~s}\left(\mathrm{FEV}_{1}\right) \%$ predicted $\left.=84.27 \%\right)$. The mean time since diagnosis was $15.62 \pm 4.48$ years.

\section{Procedure}

The present study consisted of two parts. The first consisted of a home visit during which written parent consent and/or adolescent assent/ consent was obtained and all adolescents and young adults were requested to complete a battery of questionnaires, including a measure of acceptance. The second part occurred during the first hospital visit following the home visit (mean time between home and hospital visit $65 \pm 64$ days; range one to 254 days). During this hospital visit, spirometry-related pain and distress were assessed by means of selfreport and physiological measurement (ie, heart rate). After completing the self-report measures of pain and distress, a heart rate monitor (Polar Electro, Finland) was placed and activated while the participants were seated in a quiet place. Subsequently, the spirometry procedure was performed using a Jaeger MasterScreen Body lung function analyzer (CareFusion, USA). During spirometry, individuals were seated in a glass cabin where they performed maximal inspiratory and expiratory manoeuvres through a mouthpiece. After the spirometry procedure, self-reported distress and pain during spirometry were assessed. The present study was approved by the Ethics Committees of the University Hospitals of Antwerp, Brussels and Ghent and the Sint-Vincentius Hospital, and was performed in accordance with universal ethics principles (26).

\section{Measures}

Sociodemographic information (age, sex and time since diagnosis) was obtained verbally before administration of the questionnaires.

Acceptance was assessed using a Dutch version of the acceptance subscale of the Illness Cognition Questionnaire (16,27). Acceptance is conceptualized as the perceived ability to live with the illness and to master its negative consequences (eg, "I can handle the problems related to my illness"). This subscale consists of six items rated on a 4 -point Likert scale $(1=$ not at all, $4=$ completely $)$. Item scores are summed, resulting in a total score ranging from 6 to 24, with higher scores indicating higher levels of acceptance. Psychometric research in samples involving adults with rheumatoid arthritis, multiple sclerosis, chronic pain and chronic fatigue syndrome has demonstrated adequate reliability and validity of the Illness Cognition Questionnaire $(16,27)$. Reliability of the acceptance scale in this sample was excellent (Cronbach's $\alpha=0.90$ ). 
Pain was assessed before and after spirometry. Participants were requested to rate the amount of pain they expected to experience and the amount of pain they experienced during spirometry ("How much pain do you think you will have/did you have during the spirometry?"; $0=$ no pain at all, $10=$ a lot of pain). Scores of 1 to 3 were considered to indicate mild pain, scores of 4 to 6 moderate pain, and scores of 7 to 10 severe pain (28).

Furthermore, thoughts related to pain before spirometry were assessed using a spirometry-specific measure of the Situational Catastrophizing Scale (29,30). Consistent with earlier research (31-33), the spirometryspecific Situational Catastrophizing Scale consisted of one adapted item from each subscale (Rumination: "At this moment, to what extent do you keep thinking about how much pain the spirometry measurement could cause?"; Magnification: "At this moment, to what extent do you think that, because of the pain, something serious could happen to you during the spirometry measurement?"; Helplessness: "At this moment, to what extent do you think that there is nothing you can do to stop the pain you will feel during the spirometry measurement?"). Use of situation-specific measures of catastrophizing is consistent with earlier research and was recently explicitly recommended $(29,30)$. Although repeatedly used, the three-item version of the scale has not yet been validated. Items were rated on an 11 -point Likert scale $(0=$ not at all, $10=\mathrm{a}$ lot $)$ and summed to obtain a total score. This total score varied between 0 and 30, with higher scores indicating higher catastrophizing about pain. Cronbach's $\alpha$ for the spirometry-specific Situational Catastrophizing Scale was 0.89 .

Distress was assessed using self-report and physiological recording of heart rate (variability) before and after spirometry. Before spirometry assessment, participants were requested to rate: how anxious/ tense they felt ("How anxious/tense do you feel about the spirometry?"; 0 = not anxious/tense at all, 10 = very anxious/tense); how worried they were about the result of spirometry ("How worried are you about the results of the spirometry?"; 0 = not worried at all, 10 = very worried); and how worried they were about the treatment subsequent to spirometry ("How worried are you about the treatment that will follow upon the spirometry measurement"; 0 = not worried at all, 10 = very worried). After the spirometry procedure, the level of self-reported distress during spirometry was assessed ("How anxious/tense did you feel during spirometry"; 0 = not anxious/tense at all, $10=$ very anxious/tense). Scores of 1 to 3 were considered to indicate mild distress or worry, scores of 4 to 6 moderate distress or worry, and scores of 7 to 10 severe distress or worry (28). Physiological distress before spirometry was determined by measuring heart rate and heart rate variability. Beat-to-beat fluctuations were continuously monitored using a wrist heart rate monitor with electrocardiogram precision (Polar S810, Polar Electro, Finland). Heart rate recording started at least $3 \mathrm{~min}$ before the start of the spirometry procedure and continued until spirometry measurement was complete. Because both of the manoeuvres performed during spirometry and the use of salbutamol (Ventolin, a bronchodilator inhaled during the spirometry procedure; GlaxoSmithKline BV, The Netherlands) affect physiological measures, only heart rate data recorded before the spirometry procedure were used. Using a stopwatch, a research assistant noted a timeline of events (eg, baseline monitoring, entering spirometry cabin, start spirometry). A sequence of $1 \mathrm{~min}$ preceding the start of the spirometry measurement and a baseline sequence of $1 \mathrm{~min}$ during which the participants were seated in a quiet room were extracted from the continuous heart rate recording for further analysis (Polar Precision Performance Software, Polar Electro, Finland). Measurement errors were filtered using a moderate filter power and a minimum protection zone of 6 beats $/ \mathrm{min}$. To determine the physiological stress responses (heart rate and heart rate variability), these sequences were further analyzed using Heart Rate Variability Analysis Software (Biomedical Signal Analysis Group, Department of Applied Physics, University of Kuopio, Finland). Means of heart rates and the root mean square of successive differences of interbeat intervals (RMSSD) were obtained. Previous research has shown that RMSSD is a reliable measure of heart rate variability. Higher heart rate indicates higher distress, whereas higher RMSSD is indicative of lower distress (34).

Disease severity was determined using $\mathrm{FEV}_{1} \%$ predicted measured during the spirometry procedure performed at the day of the hospital visit. $\mathrm{FEV}_{1} \%$ predicted was used as a continuous variable, with lower values indicating poorer respiratory functioning and more lung disease.

\section{Statistical analyses}

All statistical analyses were performed using SPSS version 15.0 (IBM Corporation, USA). First, preliminary analyses were performed. Tests of normality (ie, Kolmogorov-Smirnov test) were performed for all continuous variables. Descriptive statistics (mean, SD, Cronbach's $\alpha$ ) were computed for all variables of interest. Correlational analyses were performed to determine whether age, time since diagnosis, disease severity and acceptance were related to the pain and distress measures. Pearson correlations were performed in the case of normal distribution, and Spearman correlations in the case of non-normal distribution. Additionally, $t$ tests were performed to examine sex differences in pain and distress.

Separate hierarchical regression analysis (for normally distributed outcomes) or partial/Spearman correlations (for non-normally distributed outcomes) were used to investigate the explanatory value of acceptance for distress and pain. Sociodemographic and diseaserelated variables that were significantly related to the outcome variables were entered as control variables in a first step. In a second step, baseline heart rate and baseline heart rate variability were entered as control variables. Acceptance was entered in the final step.

The current sample had sufficient power $(0.80)$ to detect large effects in multiple regressions $\left(f^{2}=0.35\right)$ with three variables $(22,35)$.

\section{RESULTS}

Tests of normality (ie, Kolmogorov-Smirnov tests) revealed that the scores for the distress outcomes (self-reported and physiological) were normally distributed. Scores for expected pain, pain-related thoughts and experienced pain, however, were non-normally distributed. Inspection of skewness and kurtosis indicated these variables were skewed to the right. Log transformation of skewed variables did not result in normal distribution for these variables. Therefore, partial correlations (in case of significant control variables) or Spearman correlations (in case of nonsignificant control variables) (Table 1) were used to investigate the role of acceptance in expected pain and pain-related thoughts.

\section{Descriptive statistics}

Means, SDs and internal consistencies (Cronbach's $\alpha$ ) of all variables and correlations among age, time since diagnosis, disease severity, acceptance, and distress and pain variables are reported in Table 1 . Disease severity ranged from not severe/normal lung function (FEV $1 \%$ predicted $290 \%)$ to severe $\left(\mathrm{FEV}_{1} \%\right.$ predicted $\left.<40 \%\right)$. Of all adolescents and young adults, $38.9 \%$ had normal lung function $\left(\mathrm{FEV}_{1} \%\right.$ predicted $\geq 90 \%), 44.4 \%$ mild lung disease $\left(89 \% \geq \mathrm{FEV}_{1} \%\right.$ predicted $\geq 70 \%)$, $13.9 \%$ moderate lung disease $\left(69 \% \geq \mathrm{FEV}_{1} \%\right.$ predicted $\geq 40 \%)$ and $2.8 \%$ severe lung disease $\left(\mathrm{FEV}_{1} \%\right.$ predicted $\left.<40 \%\right)$. Of the sociodemographic and disease-related variables, only age was significantly related to heart rate before spirometry $(r=0.35 ; \mathrm{P}<0.05)$. Furthermore, $t$ tests revealed that sex was significantly related to anxiety/tension before spirometry (male $1.47 \pm 2.50$, female $3.53 \pm 2.39$; $\mathrm{F}[1,34]=6.35 ; \mathrm{P}<0.05$; Cohen's $\mathrm{d}=0.84)$, worry about results of spirometry (male 2.71 \pm 2.54 , female 5.05 $\pm 2.80 ; \mathrm{F}[1,34]=6.87 ; \mathrm{P}<0.05$; Cohen's $d=0.88$ ), pain-related thoughts (male $0.71 \pm 1.72$, female $2.89 \pm 4.05 ; \mathrm{F}[1,34]=4.26 ; \mathrm{P}<0.05 ;$ Cohen's $\mathrm{d}=0.70)$ and acceptance (male 19.94 \pm 3.40 , female 16 $\pm 4.20 ; \mathrm{F}[1,34]=9.42, \mathrm{P}<0.01$; Cohen's d $=1.03$ ), with females scoring higher on anxiety before spirometry, worry about results of spirometry and pain-related thoughts, and lower on acceptance than males. 
TABLE 1

Internal consistency (Cronbach's $\alpha$ ) and Pearson product-moment/Spearman correlations

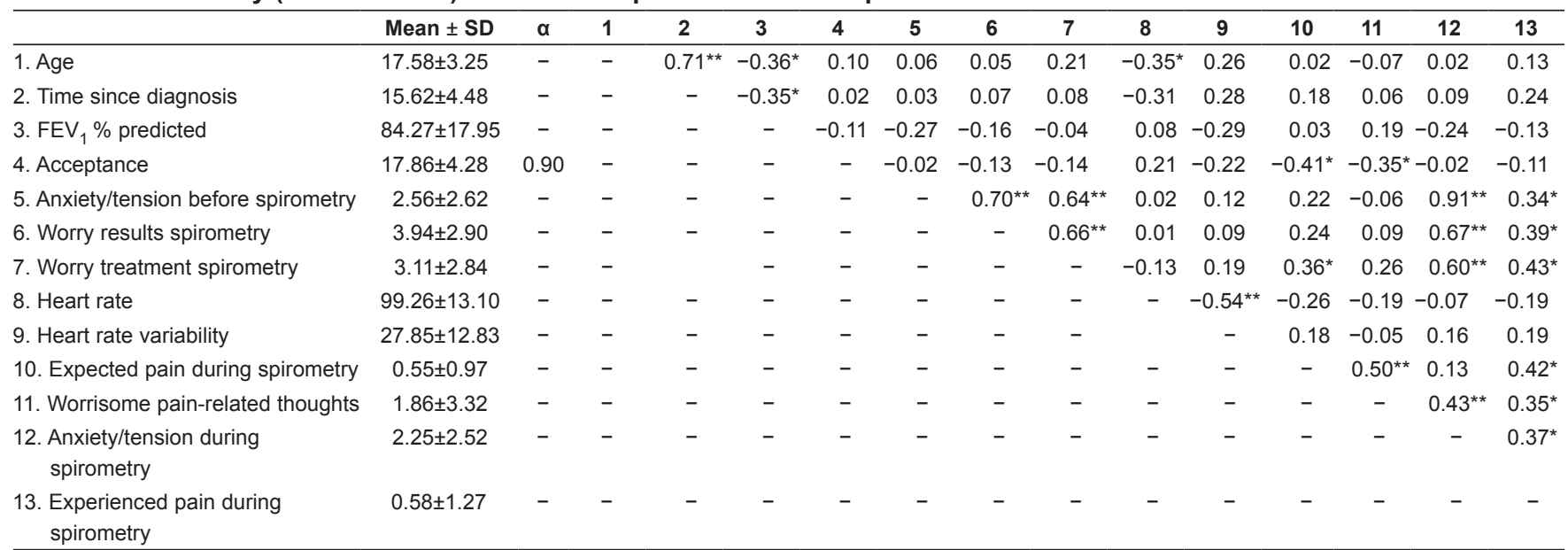

Correlations regarding expected and experienced pain are Spearman correlations; correlations regarding pain-related thoughts are partial correlations controlled for sex. ${ }^{*} P<0.05 ;{ }^{*} P<0.01$. FEV 1 Forced expiratory volume in $1 \mathrm{~s}$

Prevalence rates of spirometry-related pain and distress

In general, $27.8 \%$ of all participating adolescents and young adults expected some level of pain during spirometry. The mean level of expected pain was mild $(0.55 \pm 0.97$; median $=0$; range 0 to 3$)$. No participants expected moderate or severe pain during spirometry. The mean level of pain-related thoughts was rather low $(1.86 \pm 3.32$; median $=0$, range 0 to 10 ). Approximately $67 \%$ of all adolescents and young adults reported experienced anxiety and/or tension before spirometry $(2.56 \pm 2.62$; median $=2$, range 0 to 9$)$. Specifically, $38.9 \%$ of the adolescents and young adults experienced mild anxiety and/or tension before spirometry, $16.7 \%$ experienced moderate anxiety and/or tension, and $11.1 \%$ experienced severe anxiety and/or tension. Furthermore, $80.6 \%$ of the participants reported worries about the results of spirometry $(3.94 \pm 2.90$; median $=3.5$, range 0 to 10$)$, with $30.6 \%$ reporting mild worry, $30.6 \%$ moderate worry and $19.4 \%$ severe worry. Finally, $75 \%$ of the adolescents and young adults reported worry about the treatment subsequent to spirometry $(3.11 \pm 2.84$; median $=2.5$, range 0 to 9$)$, with $36.1 \%$ reporting mild worry, $25 \%$ moderate worry and $13.9 \%$ severe worry.

After spirometry, $22.2 \%$ of all participants reported that they had actually experienced pain during spirometry $(0.58 \pm 1.27$; median $=0$, range 0 to 5 ; mild pain: $16.6 \%$; moderate pain: $5.6 \%$; severe pain: $0 \%$ ). Furthermore, $61.1 \%$ reported to have experienced anxiety and/or tension during spirometry $(2.25 \pm 2.52$; median $=1.5$, range 0 to 9 ; mild anxiety/tension: $33.3 \%$; moderate anxiety/tension: $22.2 \%$; severe anxiety/tension: $5.6 \%$ ).

Role of acceptance in spirometry-related pain

Results indicated that more acceptance was related to less expected pain $(\mathrm{rs}=-0.41 ; \mathrm{P}<0.05)$ and fewer pain-related thoughts $(\mathrm{rs}=-0.35$; $\mathrm{P}<0.05)$. The explained variance in expected pain and pain-related thoughts, however, was small (17\% and 13\% respectively). Acceptance was not related to experienced pain during spirometry $(\mathrm{rs}=-0.11$; not statistically significant) (Table 1).

Role of acceptance in spirometry-related distress

Sex and age were entered as control variables because both variables showed significant associations with distress. Findings indicated that acceptance was not related to anxiety and/or tension before and during spirometry, nor to physiological distress and to worry about the results of and treatment subsequent to spirometry (Table 2). Examination of tolerance and variance inflation factors of all regression analyses revealed no evidence of multicollinearity.

\section{DISCUSSION}

To our knowledge, the present analysis was the first prospective study investigating spirometry-related pain and distress, and the explanatory value of acceptance in this pain and distress in adolescents and young adults with CF. The present findings are the first to indicate that some adolescents and young adults expect and/or experience pain and/or distress during spirometry. Of these adolescents and young adults, a non-negligible number reported considerable pain and distress. However, it should be noted that, as a group, adolescents and young adults with CF only reported mild expected and experienced pain, low levels of pain-related thoughts before spirometry, mild to moderate distress before spirometry and mild experienced distress during spirometry. Although acceptance was unrelated to anxiety and/or tension before/during spirometry, worry about the results of spirometry, worry about treatment subsequent to spirometry, physiological distress (heart rate and heart rate variability) before spirometry and experienced pain during spirometry, findings revealed that higher acceptance of illness related to lower levels of expected pain and fewer pain-related thoughts. Given the mild levels of expected and experienced pain in the current sample and the small portion of explained variance by acceptance, these relationships need to be interpreted with caution.

The current findings are the first to provide insight into the occurrence of pain and distress before/during spirometry in adolescents and young adults with $\mathrm{CF}$, and the explanatory value of acceptance for pain and distress. Investigating procedure/spirometry-related pain and distress is essential because both pain and distress may have a negative impact on the experience of (subsequent) spirometry and on quality of life in general (11-13). The occurrence of pain and distress in the current study was generally consistent with existing literature assuming that spirometry may be painful and/or distressing for adolescents and young adults with CF $(8,10)$. Given these prevalence rates, it can be argued that special attention should be devoted to the way adolescents and young adults experience routine spirometry. In this way, possible pain and distress can be adequately detected and managed (eg, analgesics, distraction, cognitive-behavioural interventions, etc) when necessary, and short- and long-term negative consequences of distress and pain (eg, anxiety, decreased quality of life) can be attenuated. This may particularly be the case for female adolescents and young adults because they reported more anxiety before spirometry, more worry about results of spirometry, more pain-related thoughts and less acceptance than males. Future research, however, is needed to replicate the findings of the current study concerning the occurrence of pain and distress during spirometry in male/female adolescents and young adults with CF. This research should also incorporate measures of quality of life to gain insight in the long-term consequences of this pain and distress.

The current study also revealed that acceptance of illness may have the potential to serve as a protective factor for anticipated pain during 


\begin{tabular}{|c|c|c|c|c|c|c|}
\hline Dependent variable & Step & Predictor & $\beta$ & $\mathbf{R}^{2}$ & $\Delta \mathbf{R}^{2}$ & Adjusted $\mathbf{R}^{2}$ \\
\hline & 2 & Acceptance & 0.21 & 0.19 & 0.03 & 0.14 \\
\hline \multirow[t]{2}{*}{ Worry about results } & 1 & Sex & $0.45^{*}$ & $0.17^{*}$ & $0.17^{*}$ & $0.14^{*}$ \\
\hline & 2 & Acceptance & 0.08 & 0.17 & 0.00 & 0.12 \\
\hline \multirow[t]{3}{*}{ Heart rate } & 1 & Age & -0.23 & $0.12^{*}$ & $0.12^{*}$ & $0.10^{*}$ \\
\hline & 2 & Heart rate baseline & $0.60^{\star *}$ & $0.49^{\star *}$ & $0.37^{\star *}$ & $0.46^{\star *}$ \\
\hline & 3 & Acceptance & 0.17 & 0.52 & 0.03 & 0.47 \\
\hline \multirow[t]{2}{*}{ Heart rate variability } & 1 & $\begin{array}{l}\text { Heart rate variability } \\
\text { baseline }\end{array}$ & $0.54^{* *}$ & $0.30^{* *}$ & $0.30^{* *}$ & $0.29^{* *}$ \\
\hline & 2 & Acceptance & -0.19 & 0.34 & 0.04 & 0.30 \\
\hline
\end{tabular}

${ }^{*} P<0.05 ;{ }^{* *} P<0.01$

spirometry and worrisome pain-related thoughts. These findings are, to some extent, consistent with results of previous research. For example, research involving adults with chronic pain has reliably demonstrated that acceptance is associated with lower levels of painrelated distress, pain-related anxiety and worrisome thoughts about pain (36-38). The current study, which is, to the best of our knowledge, the first to assess the role of acceptance for acute pain, partially corroborates these previous findings by demonstrating that acceptance may also be related to aspects of acute pain such as expected pain and pain-related thoughts before spirometry. However, contrary to previous research in chronic pain (36), the relationship between acceptance and experienced acute pain did not reach statistical significance in the present study.

Similarly, no evidence was obtained for the role of acceptance in spirometry-related distress (self-report and physiological measures). This is, again, contrary to previous research in pediatric chronic conditions, such as chronic pain, juvenile arthritis, CF and sickle cell disease, which has demonstrated that acceptance is inversely related to several aspects of distress in chronic illness such as positive and negative mood, anxiety and depression (17-22). The current findings are also not consistent with research in nonclinical samples showing that higher acceptance is related to less negative emotions (eg, stress, negative affect) during negative emotional experiences $(23,24)$. Although this may suggest that acceptance primarily relates to pain and distress in the context of chronic pain rather than acute pain, further research to investigate whether acceptance is important in understanding single and repeated episodes of acute pain (ie, recurrent painful medical procedures) and associated distress is warranted. One possible explanation for the lack of association between acceptance and subjective distress/pain is that the spirometry procedure was, at least for the majority of participants, insufficiently distressing/painful to elicit the beneficial effects of acceptance (24). Furthermore, with respect to the physiological assessment of distress, it may be that increased heart rate, a common symptom in individuals with $\mathrm{CF}$, masked the possible occurrence of subtle increases in heart rate due to physiological stress (39). However, it also remains possible that insufficient power to detect small and medium effects underlies the absence of a significant association between acceptance and acute experienced pain and distress. Regarding the psychophysiological measures, it is possible that acceptance is not related to heart rate before spirometry, but to the level of heart rate recovery after the experience of distress. However, this effect could not be examined in the current study because performing spirometry has, in itself, an impact on heart rate (ie, effects of salbutamol and respiratory manoeuvres).

To some extent, the current findings add to the concept that acceptance may play a protective role in the adjustment to living with chronic illness in general, and to CF in particular. In the context of $\mathrm{CF}$, acceptance comprises the ability to face the demands and limitations characteristic of $\mathrm{CF}$, and to concede to the unpredictable and uncontrollable nature of CF $(16,40,41)$. The current findings cautiously indicate that acceptance of illness may also comprise the ability to face more indirect demands of having CF such as the need to perform spirometry. Although acceptance of illness concerns adjustment to illness in general, the current findings suggest the likelihood that it also impacts very specific illness-related experiences such as expected pain during spirometry and pain-related thoughts. From adolescence onward, CF typically becomes more severe and consequently requires more intensive medical follow-up (3). Therefore, acceptance of CF may be particularly important during adolescence. Approaches addressing acceptance, such as acceptance and commitment therapy (42), already exist for several chronic conditions (eg, depression, psychosis, type 2 diabetes, sickle cell disease, epilepsy, chronic pain and substance abuse) and are promising (18,20,42-45). Further research investigating the role of acceptance in the experiences of adolescents and young adults with CF during painful and distressing medical procedures is needed to determine whether these interventions are useful for this population.

Procedure-related pain and distress in adolescents and young adults with CF has received little attention to date. The present findings are among the first of their kind and are likely a first step toward more research on this topic. However, several limitations need to be considered, each of which indicates directions for future research. First, the study only had sufficient power to detect large effects. As previously noted, it is, therefore, possible that small and medium effects remained undetected. Larger samples are needed to detect smaller effects and to investigate whether sex moderates the effects of acceptance. Second, adolescents and young adults reported, on average, low levels of distress and pain. It is possible that our results do not generalize to adolescents and young adults experiencing high pain and distress. Future research, including other physiological measures (eg, blood pressure and respiratory rates), is needed to address the impact of acceptance for more distress-evoking medical procedures such as venipuncture. Third, only 52 of 78 adolescents and young adults consented to participate, potentially reflecting sample bias. Because mean acceptance was quite high in the current sample, it is possible that the current findings do not generalize to samples scoring lower on acceptance. Future research is needed to replicate the current findings in larger and more diverse (eg, also adolescents and young adults who report severe pain, severe distress and low acceptance) samples. Fourth, there was a long time delay (mean 65 days) between the self-report of acceptance and the report of pain and distress measured during the hospital visit. This interval varied substantially among participants (SD 64 days) and may have influenced the current results (eg, effect of intermediate factors). Fifth, pain catastrophizing was measured using three items and distress with a single item. Single or low numbers of items may decrease 
statistical power to detect differences and are less reliable. Future research should include more comprehensive measures. Sixth, disease severity was only assessed by $\mathrm{FEV}_{1} \%$ predicted. Use of more complex indexes, including all aspects of disease (46), may provide a more complete representation of health status. Finally, our measure of acceptance does not fully capture the richness of the construct of acceptance as it has been developed in scientific and clinical use. To be able to assess the specifics of acceptance in individuals with CF, a measure of acceptance that focuses on the specific characteristics of CF and covers all aspects of acceptance is needed. This measure should, for example, assess the ability to face the demands and limitations typical of CF, the capability of relinquishing the struggle for change or control and reconciliation with the unpredictable and uncontrollable nature of CF. The Acceptance and Action Questionnaire (AAQ) (16,40-42) could be particularly informative in this regard. The AAQ is a generic measure that assesses ACT processes such as acceptance, values-based action and psychological flexibility. The AAQ has already been adjusted for specific conditions such as chronic pain (Chronic Pain Acceptance Questionnaire [37]) and diabetes (Acceptance and Action Diabetes Questionnaire [42]), but not yet for CF.

\section{REFERENCES}

1. Ratjen F, Döring G. Cystic fibrosis. Lancet 2003;361:681-9.

2. Rosenstein BJ, Zeitlin PL. Cystic fibrosis. Lancet 1998;351:277-82.

3. Ernst MM, Johnson MC, Stark LJ. Developmental and psychological issues in cystic fibrosis. Child Adolesc Psychiatric Clin N Am 2010;19:263-83

4. de Abreu e Silva FA, Dodge JA. Guidelines for the diagnosis and treatment of cystic fibrosis. WHO Human Genetics Programme and the International Cystic Fibrosis Association 1996.

5. Ayers S, Muller I, Mahoney L, Seddon P. Understanding needlerelated distress in children with cystic fibrosis. Brit J Health Psych 2011;16:329-43.

6. Ward CM, Brinkman T, Slifer KJ, Paranjape SM. Using behavioral interventions to assist with routine procedures in children with cystic fibrosis. J Cyst Fibros 2010;9:150-3.

7. O'Sullivan BP, Freedman SD. Cystic fibrosis. Lancet 2009;373:1891-904.

8. Miller MR, Hankinson J, Brusasco V, et al. Standardisation of spirometry. Eur Respir J 2005;26:319-38.

9. Geller DE, Rubin BK. Respiratory care and cystic fibrosis. Respir Care 2009;54:796-800.

10. Davies JC, Alton EWFW. Monitoring respiratory disease severity in cystic fibrosis. Respir Care 2009;54:606-17.

11. Chen E, Zeltzer LK, Craske MG, Katz ER. Children's memories for painful cancer treatment procedures: Implications for distress. Child Dev 2000;71:931-45.

12. Klosky JL, Tyc VL, Tong X, et al. Predicting pediatric distress during radiation therapy procedures: The role of medical, psychosocial, and demographic factors. Pediatrics 2007;119:1159-66.

13. Tucker CL, Slifer KJ, Dahlquist LM. Reliability and validity of the brief behavioural distress scale: A measure of children's distress during invasive medical procedures. J Pediatr Psychol 2001;26:513-23.

14. Rudolph KD, Dennig MD, Weisz JR. Determinants and consequences of children's coping in the medical setting: Conceptualization, review, and critique. Psychol Bull 2005;118:328-57.

15. Schechter NL, Zempsky WT, Cohen LL, et al. Pain reductions during pediatric immunizations: Evidence-based review and recommendations. Pediatrics 2007;119:1184-98.

16. Evers AWM, Kraaimaat FW, Lankveld W van, Jongen PJH, Jacobs JWG, Bijlsma JWJ. Beyond unfavorable thinking: The Illness Cognition Questionnaire for chronic diseases. J Consult Clin Psychol 2001;69:1026-36.

17. McCracken LM, Gauntlett-Gilbert J, Eccleston C. Acceptance of pain in adolescents and young adults with chronic pain: Validation of an adapted assessment instrument and preliminary correlation analyses. Eur J Pain 2010;14:316-20.

18. Wicksell RK, Olsson GL, Hayes SC. Mediators of change in acceptance and commitment therapy for pediatric chronic pain. Pain 2011;152:2792-801.

19. Feinstein AB, Forman EM, Masuda A, et al. Pain intensity, psychological inflexibility, and acceptance of pain as predictor of

\section{SUMMARY}

The current study aimed to investigate the occurrence of spirometryrelated pain and distress in adolescents and young adults with $\mathrm{CF}$, and the role of acceptance of illness. Findings indicated that a non-negligible number of adolescents and young adults with $\mathrm{CF}$ reported spirometry-related pain and distress. Furthermore, it was found that acceptance may play a protective role in the more indirect consequences of having CF such as expected pain and pain-related thoughts during medical procedures. These findings suggest that acceptance may be an important point of intervention in the management of procedure-related pain in adolescents and young adults with CF.

ACKNOWLEDGEMENTS: This work was supported by the Belgian Cystic Fibrosis Association (A06/0536). The authors thank all participants and their parents for their cooperation, Prof Dr Kristine Desager, Prof Dr Anne Malfroot, Alexandra Saey and Gwendolyn Van Cauwelaert for their help in recruiting, Eline Vercaemer and Ilke Corneilli for their help with data collection, and Marleen Vanderkerken, Ann Raman, Sylvianne De Beuckelaere and Hilde Stevens for their help during the hospital visits.

functioning in adolescents and young adults with juvenile idiopathic arthritis: A preliminary investigation. J Clin Psychol Med Settings 2011;18:291-8.

20. Masuda A, Cohen LL, Wicksell, RK, Kemani MK, Johnson A. A case study: Acceptance and commitment therapy for pediatric sickle cell disease. J Pediatr Psychol 2011;36:398-408.

21. Casier A, Goubert L, Theunis M, et al. The role of acceptance in psychological functioning in adolescents and young adults with cystic fibrosis: A preliminary study. Psychol Health 2008;23:629-38

22. Casier A, Goubert L, Theunis M, et al. Acceptance and well-being in adolescents and young adults and young adults with cystic fibrosis: A prospective study. J Pediatr Psychol 2011;36:476-87.

23. Hofmann SG, Heering S, Sawyer AT, Asnaani A. How to handle anxiety: The effects of reappraisal, acceptance, and suppression strategies on anxious arousal. Behav Res Ther 2009;47:389-94.

24. Shallcross A, Troy AS., Boland M, Mauss IB. Let it be: Accepting negative emotional experiences predicts decreased negative affect and depressive symptoms. Behav Res Ther 2010;48:921-9.

25. Cystic Fibrosis Foundation. Patient registry. Annual Data Report 2008. < www.cff.org/uploadedfiles/aboutcffoundation/ annualreport/2008-annual-report.pdf> (Accessed January 28, 2013).

26. Emanuel EJ, Wendler D, Grady C. What makes clinical research ethical? JAMA 2000;283:2701-11.

27. Lauwerier E, Crombez G, Van Damme S, Goubert L, Vogelaers D, Evers AWM. The construct validity of the Illness Cognition Questionnaire; The robustness of the three-factor structure across patients with chronic pain and chronic fatigue. Int J Behav Med 2010;17:90-6.

28. Bouhassira D, Lantéri-Minet M, Attal N, Laurent B, Touboul C. Prevalence of chronic pain with neuropathic characteristics in the general population. Pain 2008;136:380-7.

29. Campbell CM, Kronfli T, Buenaver LF, et al. Situational versus dispositional measurement of catastrophizing: Associations with pain responses in multiple samples. J Pain 2010;11:443-53.

30. Campbell CM, Quartana PJ, Buenaver LF, Haythornthwaite JA, Edwards RR. Changes in situation-specific pain catastrophizing precede changes in pain report during capsaicin pain: A cross-lagged panel analysis among healthy, pain-free participants. J Pain 2010;11:876-84.

31. Caes L, Vervoort T, Eccleston E, Vandenhende M, Goubert L. Parental catastrophizing about child's pain and its relationship with activity restriction: The mediating role of parental distress. Pain 2011;152:212-22.

32. Goubert L, Vervoort T, Cano A, Crombez G. Catastrophizing about their children's pain is related to higher parent-child congruency in pain ratings: An experimental investigation. Eur J Pain 2009;13:196-209.

33. Caes L, Vervoort T, Trost Z, Goubert L. Impact of parental catastrophizing and contextual threat on parents' emotional and behavioral responses to their child's pain. Pain 2012;153:687-95. 
34. Camm AJ, Malik M, Bigger BT, et al. Heart rate variability. Standards of measurement, physiological interpretation, and clinical use. Eur Heart J 1996;17:354-81.

35. Cohen J. A power primer. Psychol Bull 1992;112:155-9.

36. McCracken LM, Vowles KE. A prospective analysis of acceptance of pain and values-based action in patients with chronic pain. Health Psychol 2008;27:215-20.

37. McCracken LM, Vowles KE, Eccleston C. Acceptance of chronic pain: Component analysis and a revised assessment method. Pain 2004;107:159-66.

38. Vowles KE, McCracken LM, Eccleston C. Patient functioning and catastrophizing in chronic pain: The mediating effects of acceptance. Health Psychol 2008;27:S136-S143.

39. National Heart Lung and Blood Institute. Cystic fibrosis. <www.nhlbi.nih.gov/health/dci/Diseases/cf/cf_what.html> (Accessed December 1, 2011).

40. Badlan K. Young people living with cystic fibrosis: An insight into their subjective experience. Health Soc Care Community 2006;14:264-70.

41. Gjengedal E, Rustøen T, Wahl AK, Hanestad BR. Growing up and living with cystic fibrosis. Everyday life and encounters with the health care and social services - a qualitative study. Adv Nurs Sci 2003;26:149-59.

42. Hayes SC, Luoma JB, Bond FW, Masuda A, Lillis J. Acceptance and commitment therapy: Model, processes and outcomes.

Behav Res Ther 2006;44:1-25.

43. Hayes SC. Acceptance and commitment therapy, relational frame theory, and the third wave of behavioural and cognitive therapies. Behavior Therapy 2004;35:639-65.

44. Wicksell, RK, Dahl J, Magnusson B, Olsson GL. Using acceptance and commitment therapy in the rehabilitation of an adolescent female with chronic pain: A case example. Cogn Behav Pract 2005; 12:415-23.

45. Wicksell RK, Melin L, Lekander M, Olsson GL. Evaluating the effectiveness of exposure and acceptance strategies to improve functioning and quality of life in longstanding pediatric pain - a randomized controlled trial. Pain 2009;141:248-57.

46. Liou TG, Adler, FR, FitzSimmons SC, et al. Predictive 5-year survivorship model of cystic fibrosis. Am J Epidemiol 2001;153:345-52. 


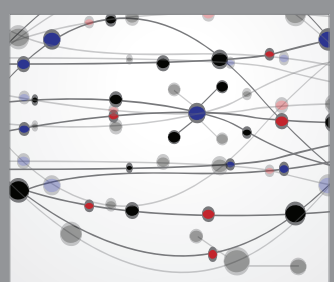

The Scientific World Journal
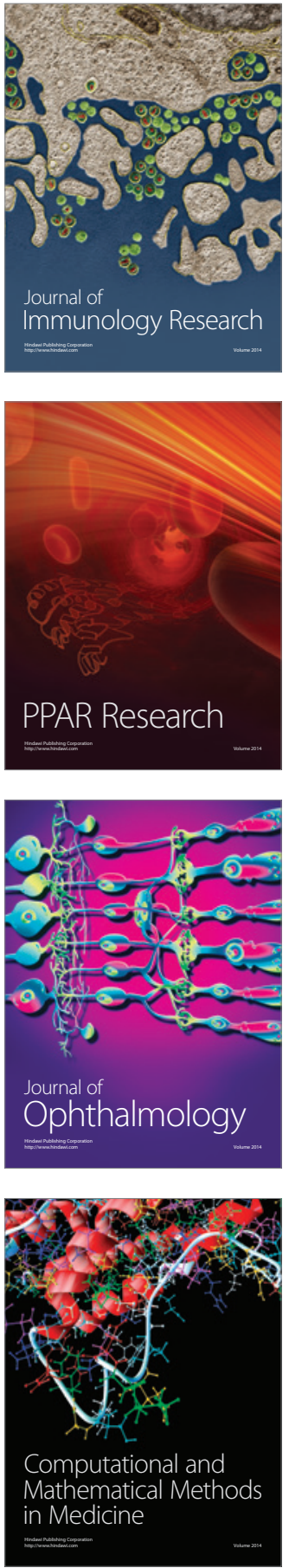

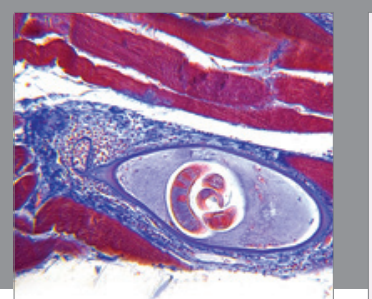

Gastroenterology Research and Practice

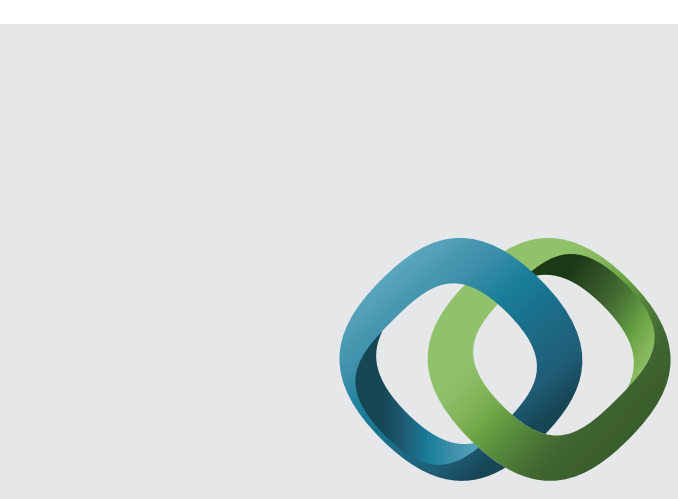

\section{Hindawi}

Submit your manuscripts at

http://www.hindawi.com
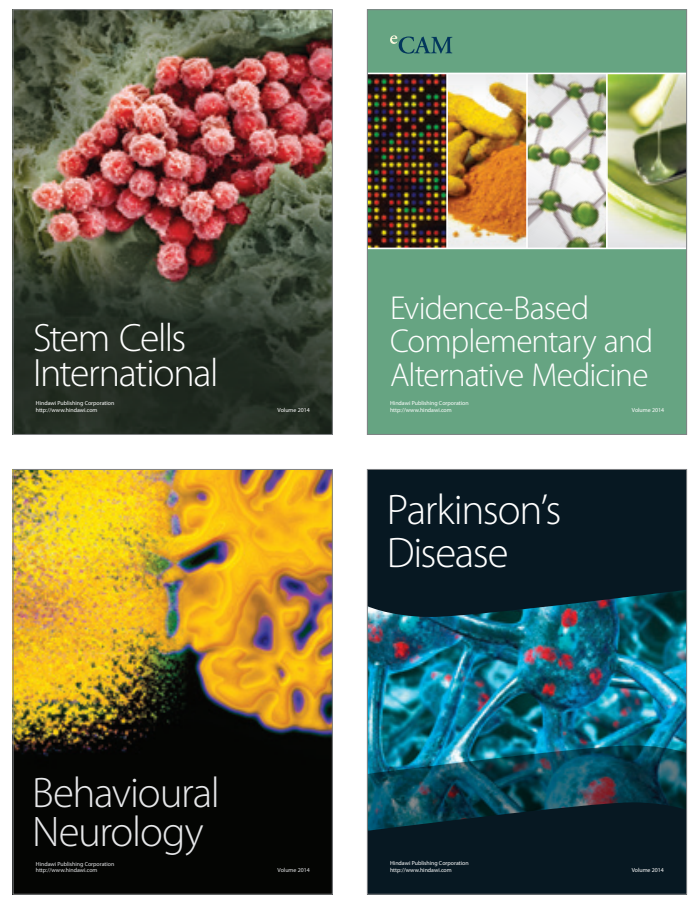
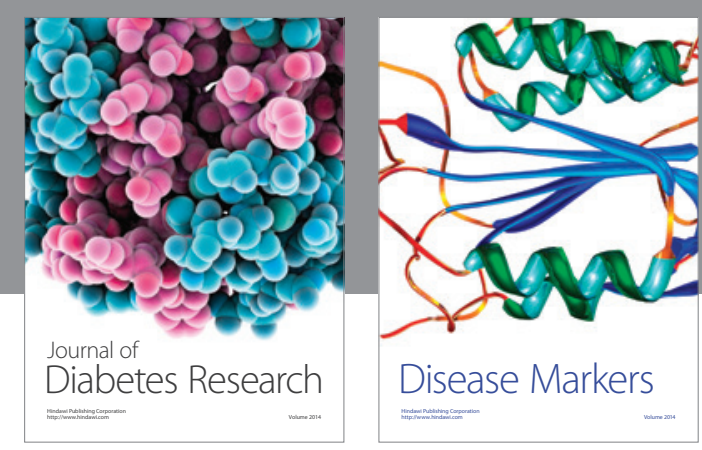

Disease Markers
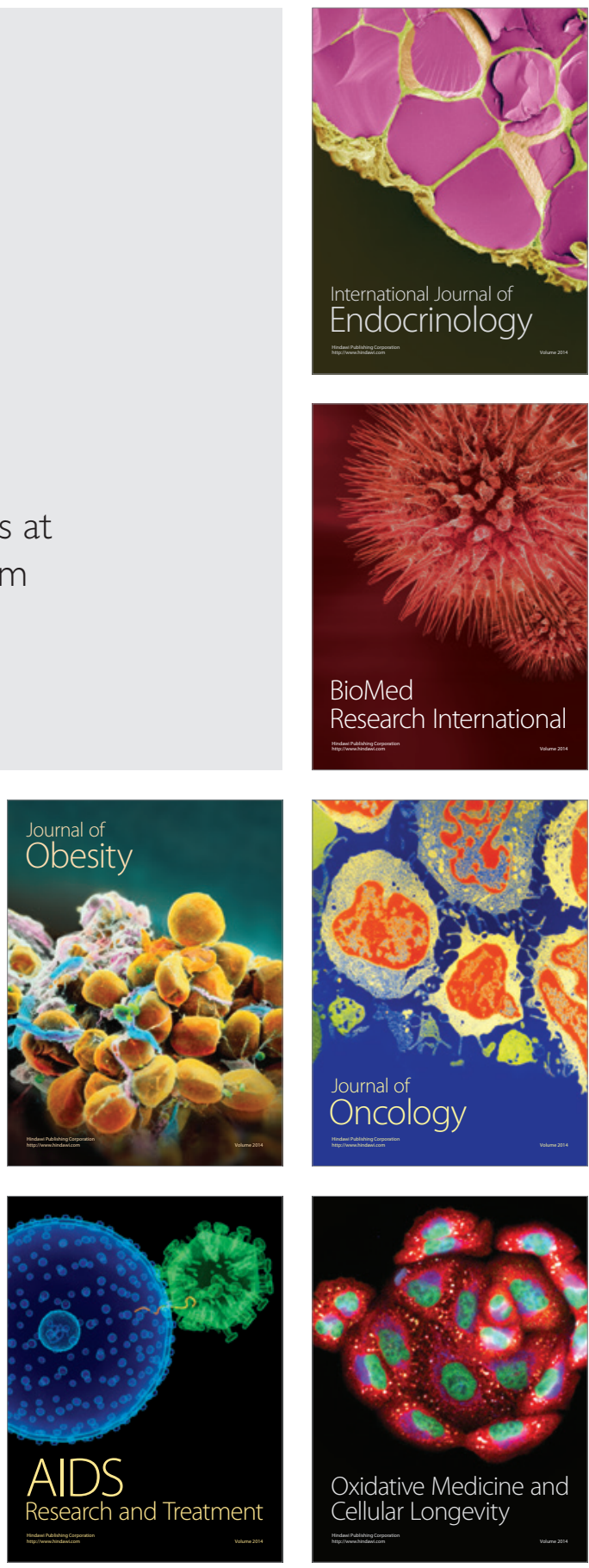